\title{
INFLUENCIA DE LA CULTURA ORGANIZACIONAL DE LAS UNIDADES DE ENFERMERÍA EN LA INTENCIÓN DE PERMANENCIA Y LAS CONDUCTAS DE CIUDADANÍA: UN ESTUDIO MULTIMUESTRA
}

\author{
INFLUENCE OF NURSING UNITS' ORGANIZATIONAL \\ CULTURE ON INTENTION TO REMAIN AND \\ CITIZENSHIP BEHAVIORS: A MULTISAMPLE STUDY
}

\author{
José PÉREZ-LARRAZABAL ${ }^{1}$, MERCEDES ARANDA-CARMENA $^{2}$ Y \\ GABRIELA TOPA $^{2}$
}

Cómo referenciar este artículo/How to reference this article:

Pérez-Larrazabal, J., Aranda-Carmena, M. y Topa, G. (2015). Influencia de la cultura organizacional de las unidades de enfermería en la intención de permanencia y las conductas de ciudadanía: un estudio multimuestra [Influence of Nursing Units' Organizational Culture on intention to remain and citizenship behaviors: A multisample study]. Acción Psicológica, 12(2), 59-72. doi: http://dx.doi.org/10.5944/ap.12.2.15754

\section{Resumen}

En el presente estudio se propone clarificar la relación de la cultura organizacional, la intención de permanencia y las conductas de ciudadanía organizacional de los profesionales de enfermería que se han incorporado a sus Unidades en los últimos doce meses. Para ello se comparan las percepciones de la cultura organizacional de los novatos con las de sus compañeros veteranos. El estudio se ha llevado a cabo con dos muestras de profesionales de enfermería españoles. La primera muestra la conforman 376 profesionales veteranos y la segunda está constituida por 162 profesionales novatos recientemente incorporados a las mismas Unidades de enfermería. En la medición de la cultura de los grupos se calcula un índice de acuerdo

Correspondencia: Gabriela Topa. Departamento de Psicología Social y de las Organizaciones, Facultad de Psicología, Universidad Nacional de Educación a Distancia (UNED), España

Email: gtopa@psi.uned.es

${ }^{1}$ Universidad de Deusto, Bilbao, España.

${ }^{2}$ Universidad Nacional de Educación a Distancia (UNED), España.

Recibido: 1 de septiembre de 2015

Aceptado: 23 de octubre de 2015 
intragupal en orden a distinguir entre grupos con cultura fuerte y con cultura débil. Se postula que el poder predictivo de la cultura sobre los resultados variará entre los grupos en función de que posean culturas fuertes o débiles y, para confirmarlo, y se aplica un análisis de regresión jerárquica. Los resultados se discuten en orden a la consideración de nuevas líneas de investigación.

Palabras clave: cultura organizacional; enfermería; conductas de ciudadanía organizacional; intención de permanencia.

\begin{abstract}
This study attempts to clarify the relationship between organizational culture, intention to remain and organizational citizenship behaviors within newcomer professional nurses who have joined the Nursing Unit during the last six months. In order to do so, newcomers' and veterans' perceptions of organizational culture have been compared. The study has been conducted with two samples of Spanish professional nurses. The first includes 376 veterans and the second is constituted by 162 novice professionals recently incorporated to the same Nursing Units. Related to assessment of organizational culture, an index of intragroup agreement is calculated and it is used to distinguish between groups with strong shared culture, and groups with weak shared culture. It is hypothesized that the predictive power of culture on outcomes will vary depending on the group shared culture (strong vs. Weak). To test this hypothesis, a hierarchical regression analysis was performed. Discussion of results is followed by a consideration of new lines of research suggested by the findings.
\end{abstract}

Keywords: organizational culture; nursing; organizational citizenship behaviors; intention to remain.

\section{Introducción}

En numerosas organizaciones sanitarias actuales, los nuevos profesionales de enfermería se incorporan a grupos de trabajo ya constituidos. Estos grupos, que han compartido una trayectoria y un conjunto de experiencias más o menos comunes, habrán desarrollado una cultura organizacional. Por cultura organizacional se entiende el conjunto de supuestos básicos y creencias que son compartidos por los miembros de la organización (Schein, 1991). Así, los novatos no se incorporan a un vacio social, sino que, al parecer, resultan influidos por las características de dicha cultura organizacional (Wang, Zhan, McCune y Truxillo, 2011).

Una de las premisas más difundidas en relación con la cultura organizacional es que ésta ejerce una influencia decisiva en la productividad de las organizaciones. En este sentido, hay un nutrido grupo de trabajos empíricos que señalan el impacto de la cultura organizacional en los resultados como la productividad o la toma de decisiones basada en la evidencia, entre otros (Chatman, Caldwell, O'Reilly y Doerr, 2014; Wei, Samiee y Lee, 2014; Wick et al., 2015).

Numerosos estudios han destacado la importancia de la cultura organizacional en diversos ámbitos laborales, como el sanitario, el educativo y el militar (Alarcon, Lyons y Tartaglia, 2010; Glisson y James, 2002; Hemmelgarn, Glisson y Dukes, 2001; Kaissi, Kralewski, Curoe, Dowd y Silversmith, 2004). No obstante, la mayoría de ellos no exploran las diferencias entre las percepciones de veteranos y novatos, dando así por sentado que los segundos asumirán las características de la cultura con un grado de consenso similar al de los primeros, ni tampoco analizan la relación de tales diferencias con los comportamientos de los recién llegados (Thomas y Anderson, 1998, 2005). 


\section{Cultura organizacional y dimensiones que la componen}

La cultura organizacional ha sido definida como el conjunto de valores, normas, actitudes y creencias compartidas por un grupo de personas (Schein, 1991), que éstas han desarrollado a partir de su experiencia en la solución de problemas de adaptación externa y de convivencia interna y que han funcionado de manera suficientemente aceptable como para ser propuestos a los nuevos miembros como la forma correcta de pensar y sentir sobre la realidad. Desde una concepción interaccionista, la cultura es el resultado de las sucesivas renegociaciones de los miembros de un grupo que acaban compartiendo un conjunto de supuestos y de percepciones básicas (Hosking y Morley, 1991). De esto se desprende, por tanto, que no todos los grupos alcanzan el mismo nivel de acuerdo en tales percepciones $\mathrm{y}$, por tanto, que no todos los grupos llegan a construir una cultura fuerte (Chatman et al., 2014).

La cultura organizacional se evalúa por diferentes procedimientos. Algunos autores se han centrado en la evaluación de las normas o las prácticas más frecuentes dentro de una Unidad de trabajo, como manifestación de su cultura (Cooke y Rousseau, 1988; Cooke y Szulman, 2000). La variedad de dimensiones incluidas en los instrumentos para medir la cultura es amplia, pero en muchas de ellas destacan características como la integración y colaboración o la cohesión y colegialidad (Kaissi et al., 2004), en función de la etiqueta asignada por los diversos autores. En este sentido, estudios precedentes han mostrado la importancia de la cohesión en el desempeño, y su influencia sobre el bienestar y la preparación psicológica para la tarea (Oliver, Harman, Hoover, Hayes y Pandhi, 1999) en diferentes contextos.

La cohesión es la unificación del grupo o el acuerdo con normas y prácticas compartidas, de tal modo que indica la disponibilidad a realizar una tarea conjunta o alcanzar objetivos que los miembros no podrían conseguir individualmente. La dimensión colegialidad se refiere a una cultura que promueve la comunicación y la coordinación entre enfermeras y entre éstas y los médicos. La dimensión de autonomía enfatiza el reconocimiento de las enfermeras, el respeto de su individualidad y la estimación de ellas por su valor personal.

\section{Novatos y veteranos: un ajuste progresivo a la cultura organizacional}

Una preocupación de la mayoría de las organizaciones es la medida en la que los novatos se integran dentro de ellas y, por consiguiente, invierten cuantiosos recursos para que tal ajuste sea rápido y duradero (Bauer y Erdogan, 2014). La literatura en socialización organizacional ha explicado las etapas y las fuentes de las cuales los novatos recaban información valiosa durante la integración y los mecanismos o tácticas que las organizaciones suelen arbitrar para lograr resultados más exitosos (Bauer, Morrison y Calister, 1998; Louis, 1990; O’Reilly, Caldwell y Chatman, 2014).

Debido a que la productividad organizacional depende, en gran medida, de las conductas de los profesionales que las integran, en particular de aquellas que exceden los requerimientos del puesto de trabajo (Birgit, Gunnevi y Ann, 2013), los esfuerzos se dirigen a favorecer tales comportamientos. Para ello, las organizaciones invierten ingentes cantidades de recursos en la selección, formación y socialización de los nuevos miembros. Sin embargo, los resultados no siempre son los deseados. Un número significativo de profesionales novatos abandona sus organizaciones en el primer trimestre de desempeño del puesto y obliga a éstas a reiniciar el proceso en búsqueda de empleados más apegados (Sheridan, 1992; Tzeng, Ketefian y Redman, 2002; Wang et al., 2011). Otra parte relevante de los nuevos empleados no alcanza a desarrollar comportamientos que favorezcan el logro eficaz de los objetivos organizacionales, aunque permanezca en la organización durante un tiempo más prolongado (Bauer, Bodner, Erdogan, Trujillo y Tucker, 2007; Bauer y Erdogan, 2011, 2014).

La mayoría de los estudios pronostica que, a medida que avanza el tiempo en un grupo de trabajo, las percepciones compartidas por novatos y veteranos se asemejan, tal como se muestra en estudios longitudinales efectuados en el Ejército británico (Thomas y Anderson, 1998). Si la 
socialización tiene por meta el ajuste a la cultura organizacional, es posible que el resultado más relevante de dicho proceso sea la ausencia de discrepancias entre los novatos y los veteranos en las percepciones de la cultura luego de transcurrido un lapso de tiempo dentro de su Unidad de trabajo.

\section{Intención de permanencia y conductas de ciuda- danía organizacional}

Las personas se integran en las organizaciones, en parte, con la expectativa de que su participación en ellas satisfaga ciertas necesidades personales que no pueden cubrir sin dicha pertenencia. En la medida en que tales necesidades resulten colmadas, las personas se sentirán más complacidas y permanecerán ligadas a la organización (Weiss, Dawis, England y Lofquist, 1967). Así, entre los indicadores de una socialización eficaz, con frecuencia se ha recurrido a la intención de permanencia (Cooper-Hakim y Viswesvaran, 2005; Langkamer y Ervin, 2008) y a las OCB. Éstas se definen como las acciones positivas ejecutadas por los empleados, pero que no forman parte del conjunto de tareas obligatorias del puesto, sino que son discrecionales y voluntarias (Dávila y Finkelstein, 2010; Lee y Allen, 2002). Su valor reside en la aportación que tales conductas hacen a la productividad global de la organización.

Ahora bien, en primer lugar, algunos estudios demuestran que la cultura podría configurar las actitudes y conductas de los miembros de los grupos a través del mecanismo psicológico de ajuste entre la persona y la organización (O’Reilly y Chatman, 1996). En concreto, el estudio más reciente de Wang y sus colaboradores (2011) ha mostrado que el ajuste de la persona con el ambiente media en la relación entre la adaptación de los novatos a la cultura organizacional y su comportamiento en el puesto. En este sentido, es posible que existan diferencias entre los grupos con cultura fuerte y los grupos con cultura débil en cuanto a las conductas de permanencia y de ciudadanía que manifiesten los participantes novatos.

En segundo lugar, un importante cúmulo de trabajos empíricos muestra que las características de la cultura organizacional impactan directamente en el funcionamiento y la productividad de las organizaciones a través de su capacidad para influir en las actitudes y conductas de los trabajadores. Entre otros resultados, la cultura organizacional influye en la satisfacción laboral, el compromiso organizacional, la calidad del servicio, el abandono del puesto, la adopción de cambios organizacionales (Glisson y James, 2002; Hemmelgarn, Glisson y Dukes, 2001; Lyons, Alarcon, Nelson y Tartaglia, 2009). En la sanidad, en concreto, se ha verificado la influencia sobre la satisfacción de los pacientes y la adopción de prácticas de calidad (Kaissi et al., 2004; Tzeng et al., 2002). Así, es posible que las características de la cultura organizacional ejerzan influencia sobre las conductas de los integrantes de dichas organizaciones.

Por estas razones, el presente estudio tiene tres objetivos. (a) En primer lugar, analizar la semejanza en la cultura organizacional percibida por los novatos en comparación con los veteranos dentro de las Unidades de enfermería de diversos hospitales. Este grado de acuerdo se usará para distinguir aquellas Unidades que han alcanzado una cultura organizacional, designadas como grupos con cultura fuerte, de aquellas que no lo han hecho, designadas como grupos con cultura débil. (b) En segundo lugar, verificar si la existencia de acuerdo en la percepción de la cultura organizacional se relaciona con la intención de permanencia y con las conductas de ciudadanía organizacional (organizational citizenship behaviors, en adelante $\mathrm{OCB}$ ) de los novatos. (c) Por último, mostrar que el impacto de la cultura organizacional sobre la intención de permanencia y las OCB de los novatos es diferente en función de que el grupo de trabajo tenga una cultura fuerte o débil.

Esto nos permitirá conocer, en primer lugar, la semejanza en la cultura organizacional percibida por los novatos en comparación con los veteranos. En segundo lugar, nos permitirá establecer si la existencia de acuerdo en la cultura organizacional percibida se relaciona con la intención de permanencia y con las OCB de los novatos. Por último, nos permitirá saber si el impacto de la cultura organizacional en la intención de permanencia y las OCB de los novatos varía en función de que el grupo de trabajo posea una cultura fuerte o débil. 


\section{Método}

\section{Participantes}

El presente estudio se ha llevado a cabo con dos muestras de participantes (profesionales de enfermería españoles). La primera estaba compuesta por 376 profesionales veteranos agrupados en 13 Unidades de enfermería. La segunda estaba compuesta por 162 profesionales de reciente incorporación que se unieron a las mismas Unidades de enfermería las que pertenecían sus compañeros veteranos. Las Unidades de enfermería se dedicaban a tareas diversas: hospitalización, cuidados intensivos, consultas externas, pediatría y neonatología, urgencias generales, urgencias materno-infantiles, cirugía y hospital de día, etc. Todos los grupos llevan trabajando juntos el mismo tiempo, aunque se pueden haber producido cambios de miembros. La muestra final que aporta datos está constituida por 529 participantes.

En cuanto a las características sociodemográficas de los novatos, su media de edad era de $26.2(S D=2.8)$. Entre los veteranos, la media de edad era de $40.3(S D=$ 5.6) y la antigüedad en el ejercicio de la profesión era de 13.8 años $(S D=3.4)$. La medios de años permanencia en la actual organización eran de 6.4 (SD $=6.2$ ) y la media de años de pertenencia a la Unidad de enfermería actual eran $5.6(S D=4.2)$. El $88.1 \%$ de los participantes trabajaban a jornada completa. Solo había un $12,8 \%$ de varones entre los participantes. En cuanto a la distribución por especialidad, había un $28.7 \%$ en Unidades de urgencias, $23.5 \%$ en consultas externas, $26.7 \%$ en hospitalización, $10.3 \%$ en maternidad, $2.1 \%$ en cirugía, y el resto en diversas unidades. La distribución de participantes en las diferentes unidades oscilaba entre aquellas donde sólo se recogieron datos de dos participantes, y las que mostraron tasas de respuesta superiores, donde se recogieron datos de un máximo de 98 integrantes. La media de número de participantes de las Unidades fue de 56.8(19.9).

\section{Procedimiento}

Para llevar a cabo el presente estudio se contó con la colaboración de los estudiantes del Máster de Investigación en Psicología de la UNED. Cada estudiante recogió cuestionarios en una Unidad de enfermería y realizó su tarea a cambio de créditos académicos de carácter práctico entre octubre de 2013 y junio de 2014. Las Unidades de enfermería encuestadas pertenecían a diferentes hospitales, ubicados en Madrid, País Vasco y Andalucía. Se explicó a todos los colaboradores los criterios de inclusión de ambos grupos de participantes (estar trabajando en la Unidad desde hacía más de tres años para los veteranos y haberse incorporado en los últimos doce meses a la Unidad para el caso de los novatos) y se les instruyó en el procedimiento a emplear durante la recolección de datos, a fin de homogeneizar la administración del cuestionario. Los participantes fueron informados de los objetivos generales del estudio, de su anonimato, y del tratamiento global de sus respuestas únicamente para fines académicos, tras lo cual expresaron su voluntariedad de participar a través de un documento de consentimiento informado. Los cuestionarios cumplimentados fueron recogidos en sobres cerrados por los colaboradores que los remitieron al equipo investigador. Se distribuyeron 800 cuestionarios y se recibieron 560 cuadernillos completos $(70 \%$ tasa de respuesta), de los que fueron considerados inválidos aquellos que contenían más del 20\% de datos perdidos.

\section{Instrumentos de evaluación}

Cultura de la Unidad de Enfermería: se aplicó el cuestionario de Cultura de los grupos sanitarios (Culture of Medical Group Practices) de Kaissi y sus colaboradores (2004). El cuestionario original en inglés se tradujo al español. Varios expertos en psicología social adaptaron los ítems desde el original. Una nueva traducción al español se llevó a cabo luego por parte de un hablante nativo inglés, que desconocía el cuestionario original, y se comparó con la escala inglesa, resolviendo así las diferencias. La escala final incluida en el presente estudio tenía tres 
subescalas que recogen información referida a conductas de cohesión $(\alpha=.86)$, colegialidad $(\alpha=.84)$ y autonomía $(\alpha=.81)$, conteniendo cinco ítems la primera subescala y seis ítems la subescala de colegialidad y tres la de autonomía. El cuestionario se introducía con la siguiente indicación: "Piensa en cómo es tu Unidad de enfermería la mayor parte del tiempo. Indica si las siguientes son características de tu Unidad". La escala de respuesta tipo Likert constaba de cinco puntos, desde $0=$ Nada característica a $4=$ Muy característica. . Las escalas completas se ofrecen en el anexo. Esta escala fue respondida tanto por los participantes veteranos como por los novatos.

Intención de Permanencia de la Organización: se midió con la subescala de intención de permanecer del Minnesota Satisfaction Questionnaire (Weiss, Dawis, England y Lofquist, 1967), cuya escala de respuesta tipo Likert constaba de cinco puntos desde 0 (Totalmente en desacuerdo) hasta 4 (Totalmente de acuerdo). Ejemplos de los ítems son "Yo tengo la intención de quedarme en esta organización para mejorar mi carrera".

$O C B$ : Se utilizó una adaptación al español (Dávila y Finkelstein, 2010) de la escala diseñada por Lee y Allen (2002). Este instrumento tiene la ventaja de que permite evaluar tanto los comportamientos de ciudadanía organizacional dirigidos a la organización como los que están dirigidos a los individuos, a diferencia de otras escalas que sólo se centran en la perspectiva de la institución. Esta escala, formada por 16 ítems con formato de respuesta tipo Likert de 5 puntos pide a los sujetos que informen con qué frecuencia cada afirmación del cuestionario se ajusta a sus propios comportamientos en el entorno laboral. La escala de respuesta tipo Likert iba de 1 (Nada frecuente) a 5 (Muy frecuente). Ejemplos de los ítems son: "Ayudo a otros compañeros que han estado ausentes", "Ajusto mi horario de trabajo para adaptarme a los necesidades de tiempo libre de otros empleados", "Defiendo a la organización cuando otros empleados la critican", "Demuestro preocupación sobre la imagen de la organización". En el presente estudio, la fiabilidad fue adecuada alcanzando un $\alpha=.79$.

\section{Diseño y análisis de datos}

En el presente estudio de tipo correlacional se han utilizado las dimensiones de cohesión, colegialidad y autonomía por su importancia para la tarea específica de las Unidades de enfermería. El análisis de la cultura organizacional requiere la demostración de que se cumplen ciertos supuestos estadísticos que son requisitos previos, siguiendo el modelo de cambio de referente propuesto por Chan (1998).

En aquellas investigaciones, como la presente, en que se intentan medir constructos no sólo en el plano individual, sino también en el plano grupal u organizacional, con frecuencia los datos obtenidos en el plano individual son agregados para operativizar los citados constructos. En tales casos, los investigadores implícita o explícitamente proponen un modelo de composición para sus constructos (Klein, Conn, Smith, y Sorra, 2001). Estos modelos de composición especifican las relaciones funcionales entre constructos que se refieren al mismo contenido pero describen fenómenos cualitativamente diferentes en el plano individual y en el plano de los grupos (Chan, 1998). Los modelos usados para agregar los datos juegan un papel importante en las inferencias que relacionan por ejemplo, las características del grupo de trabajo con las variables de resultados en el plano individual. Chan propone el modelo de cambio de referente, que aquí se ha adoptado, ya que se han formulado los ítems con referencia al grupo y no a las percepciones individuales, porque la cultural organizacional es una propiedad del sistema social o del grupo de trabajo y no del individuo, y esta diferencia se refleja en el cambio de referente de lo individual a lo colectivo, calculándose también los estadísticos que se recomiendan (Chan, 1998). Para asegurar el cumplimiento de las condiciones que justifican el agregado de las respuestas individuales dentro del grupo de trabajo como una representación de un constructo de nivel grupo es necesario demostrar el acuerdo intragrupo. Si no hay acuerdo intragrupo las respuestas individuales no se pueden componer, ya que la falta de consenso sugiere que las expectativas comunes y las normas no se han consensuado adecuadamente. Para operativizar el acuerdo intragrupo en este estudio hemos usado el índice de Lindell (2001). Los autores mantienen posiciones discrepantes respecto al valor que puede ser empleado como criterio de acuerdo razonable entre los miembros del grupo y son diversos los que consideran 
que aquellos valores superiores a .60 puede considerarse un nivel de acuerdo suficiente. Finalmente, para verificar el impacto de las características de la cultura sobre la intención permanencia y las OCB se efectúan análisis de regresión jerárquica por pasos, pronosticando la intención de permanencia y las OCB en los grupos con cultura fuerte y en cultura débil

\section{Resultados}

En primer lugar, en el presente trabajo se analizaron los índices de acuerdo intragrupo que permitían establecer si existía o no suficiente consenso para afirmar la existencia de una cultura organizacional. En la Tabla 1 se recogen los valores de los índices de Lindell para cada dimensión y cada Unidad de enfermería.

En relación con el análisis de la semejanza en la cultura organizacional percibida por los novatos en comparación con los veteranos se hallaron los siguientes resultados:

El índice de acuerdo de Lindell permite valorar las características de la cultura en aquellas unidades en las que el nivel de acuerdo intragrupo es superior a .60, por lo que nos referimos a las unidades Hospitalización (grupo b y grupo $c$ ), Urgencias generales (grupo b), Consultas externas (grupo a y grupo b), Maternidad, y Cirugía como grupos con cultura fuerte. A la par, se ha considerado que no alcanza suficiente acuerdo intragrupal, y por lo tanto no puede analizarse la cultura en las unidades Hospitalización (grupo a), Urgencias generales (grupo a), Urgencias generales (grupo c) y Urgencias de pediatría. En lo sucesivo nos referiremos a éstos como grupos con cultura débil.

Una vez comprobado el requisito previo relativo al acuerdo intragrupo, se procedió a analizar las diferencias existentes en las dimensiones de la cultura entre los miembros veteranos y los novatos por medio del análisis de la varianza. El estadístico $F$ se basa en el supuesto de la de homocedasticidad, que con grupos de distintos tamaños debe ser cuidadosamente verificado y, en caso de incumplimiento, obliga a utilizar la alternativa de los estadísticos de Brown-Forsythe y Welch cuando no se pueden asumir varianzas iguales. Por lo tanto, y como condición previa para el ANOVA, se verificó la homogeneidad de la varianza a través del estadístico de Levene.

Los resultados del análisis de homocedasticidad indican que la varianza no es homogénea para la unidad Urgencias generales - grupo $a$ - en la dimensión de cohesión (Estadístico de Levene $=4.51, p<.05$ ), para las Urgencias generales -grupo $b$ - (Estadístico de Levene $=$ 4.77, $p<.05)$, Consultas externas -grupo $a-$ (Estadístico

Tabla 1

Índices de acuerdo interjueces (Lindell) en función de las unidades

\begin{tabular}{|c|c|c|c|}
\hline Unidades de enfermería & Cohesión & Colegialidad & Autonomía \\
\hline Hospitalización (grupo a) & .63 & .70 & .73 \\
\hline Hospitalización (grupo b) & .77 & .75 & .80 \\
\hline Hospitalización (grupo c) & .77 & .86 & .78 \\
\hline Urgencias generales (grupo a) & .56 & .80 & .69 \\
\hline Urgencias generales (grupo b) & .77 & .82 & .72 \\
\hline Urgencias generales (grupo c) & .73 & .84 & .75 \\
\hline Urgencias de pediatría & .79 & .76 & .77 \\
\hline Consultas externas (grupo a) & .67 & .70 & .65 \\
\hline Consultas externas (grupo b) & .64 & .78 & 79 \\
\hline Cuidados intensivos (grupo a) & n.d. & n.d. & n.d. \\
\hline Cuidados intensivos (grupo b) & n.d. & n.d. & n.d. \\
\hline Maternidad & .68 & .70 & .74 \\
\hline Cirugía & .79 & .82 & .78 \\
\hline
\end{tabular}

Nota. n. d. no disponible 
Tabla 2

Análisis de varianza de las dimensiones de la cultura organizacional en función de las Unidades de enfermería

\begin{tabular}{|c|c|c|c|c|c|c|c|c|c|c|c|}
\hline \multirow{3}{*}{$\begin{array}{l}\text { Dimensiones de la } \\
\text { cultura } \\
\text { organizacional }\end{array}$} & \multicolumn{11}{|c|}{ Unidades de enfermería } \\
\hline & \multicolumn{3}{|c|}{ Hospitalización } & \multicolumn{3}{|c|}{$\begin{array}{l}\text { Urgencias } \\
\text { generales }\end{array}$} & \multirow{2}{*}{$\begin{array}{l}\text { Urgencias } \\
\text { de pediatría }\end{array}$} & \multicolumn{2}{|c|}{$\begin{array}{c}\text { Consultas } \\
\text { externas }\end{array}$} & \multirow{2}{*}{ Maternidad } & \multirow{2}{*}{ Cirugía } \\
\hline & (a) & (b) & (c) & (a) & (b) & (c) & & (a) & (b) & & \\
\hline Cohesión $F$ & 1.0 & .007 & 3.1 & $7.7^{*}$ & .03 & $9.8^{* *}$ & .16 & $5.7^{*}$ & .19 & .24 & .00 \\
\hline Colegialidad $F$ & $4.2^{*}$ & .87 & 2.0 & $8.3^{* *}$ & 3.1 & 1.0 & .17 & .58 & .91 & 3.8 & $16.8^{* *}$ \\
\hline Autonomía $F$ & $21.4^{* \star *}$ & 3.4 & 3.7 & $6.2^{*}$ & $4.5^{\star}$ & .21 & 3.1 & 1.2 & .55 & 2.2 & 5.9 \\
\hline
\end{tabular}

Nota. (a): grupo a; (b): grupo b; (c): grupo c.

${ }^{* * *} p<.001,{ }^{* *} p<.01,{ }^{*} p<.05$.

de Levene $=4.36, p<.05)$ y Urgencias generales - grupo $c-$ (Estadístico de Levene $=14.27, p<.001)$ en la autonomía, para la unidad de Cirugía en autonomía (Estadístico de Levene $=4.99, p<.05)$ y colegialidad (Estadístico de Levene $=4.2, p<.05)$ y para la unidad de Urgencias en pediatría en cohesión (Estadístico de Levene $=4.84, p<.05$ ), por lo cual se recurre a las alternativas robustas a $F$.

Para poner a prueba la primera hipótesis se procede al análisis de la varianza cuyos resultados se muestran en Tabla 2.

Casi todos los grupos de cultura débil muestran diferencias significativas al menos en una de las dimensiones de la cultura, excepto la unidad de Urgencias en pediatría. En concreto, la unidad de Hospitalización (grupo a) presenta diferencias entre novatos y veteranos en dos dimensiones, la unidad de Urgencias generales (grupo a) en las tres dimensiones evaluadas y la unidad de Urgencias generales (grupo c) en una de ellas. Entre los grupos de cultura fuerte, sólo las unidades de Urgencias generales (grupo b), Consultas externas (grupo a) y Cirugía muestran diferencias significativas en la percepción de alguna dimensión de la cultura entre los miembros nuevos y los veteranos, siendo en la dimensión de autonomía para la unidad Urgencias generales (grupo b), en la de cohesión para la unidad de Consultas externas (grupo a) y en la colegialidad para la unidad Cirugía.

En cuanto al segundo objetivo, se verifica en el presente estudio que existen diferencias significativas entre los grupos con cultura fuerte y con cultura débil en la intención de permanencia y en las OCB de los novatos. Los resultados muestran que hay diferencias estadísticamente significativas entre los grupos con cultura fuerte y con cultura débil para la intención de permanencia $(F=$ $5.03, p<.05, \eta 2=.04)$ y para las OCB $(F=4.26, p<$ $.05, \eta 2=.03$ ). Estos resultados nos permiten ver que hay diferencias estadísticamente significativas en función de la cultura de los grupos en ambos indicadores del comportamiento de los miembros novatos.

En relación con el tercer objetivo, mostrar que el impacto de la cultura organizacional sobre la intención de permanencia y las $O C B$ de los novatos es diferente en función de que el grupo de trabajo tenga una cultura fuerte o débil, los resultados muestran que las dimensiones de la cultura organizacional pronostican de forma estadísticamente significativa las actitudes y conductas de los participantes, en aquellos grupos considerados con cultura fuerte, pese a que los porcentajes de varianza explicada no son excesivamente altos. En los grupos con cultura débil, el poder predictivo de las dimensiones de la cultura se ve reducido, ya que no logran pronosticar la intención de permanencia, ni las OCB. Además, el porcentaje de varianza explicado es superior para los grupos con cultura fuerte que para los grupos con cultura débil como puede verse en la Tabla 3. 
Tabla 3

Análisis de regresión jerárquica pronosticando intención de permanencia y OCB en grupos con cultura fuerte y grupos con cultura débil

\begin{tabular}{|c|c|c|c|c|}
\hline \multirow{3}{*}{ Predictores } & \multicolumn{4}{|c|}{ Variable Criterio } \\
\hline & \multicolumn{2}{|c|}{ Intención de permanencia } & \multicolumn{2}{|c|}{ OCB } \\
\hline & $\Delta R^{2}$ & $\beta$ & $\Delta R^{2}$ & $\beta$ \\
\hline \multicolumn{5}{|c|}{ Grupos con cultura fuerte } \\
\hline Cohesión & .01 & .11 & .01 & -.12 \\
\hline Autonomía & $.05^{*}$ & .30 & $.06^{*}$ & -.32 \\
\hline Colegialidad & $.06^{* *}$ & .38 & .00 & .10 \\
\hline Total $R^{2}$ & $.10^{* *}$ & & $.08^{*}$ & \\
\hline \multicolumn{5}{|c|}{ Grupos con cultura débil } \\
\hline Cohesión & .005 & .07 & 01 & -.11 \\
\hline Autonomía & .049 & .25 & .00 & -.01 \\
\hline Colegialidad & .003 & -.10 & .009 & -.19 \\
\hline Total $R^{2}$ & .056 & & .022 & \\
\hline
\end{tabular}

Nota. ${ }^{* *} p<.01,{ }^{*} p<.05$.

\section{Discusión}

El objetivo de este trabajo era triple. En primer lugar, comparar las percepciones sobre la cultura organizacional de los miembros recién llegados con las de sus compañeros veteranos dentro de las Unidad de enfermería. En segundo lugar, verificar si existía acuerdo en las dimensiones de la cultura organizacional y, en caso de existir, si dicho acuerdo se relaciona de forma significativa con las actitudes (intención de permanencia) y con las conductas $(\mathrm{OCB})$ de los participantes novatos. Por último, en el presente trabajo se pretendía mostrar que las características de la cultura organizacional impactaban sobre los resultados personales de los miembros novatos y que dicho impacto resultaba diferente para los grupos en función de que poseyeran una cultura fuerte o débil. Pese a algunas limitaciones que se señalarán oportunamente, el presente estudio tiene el mérito de alcanzar tales objetivos y de hacerlo a través de un diseño multimuestra, en el cual se recogieron datos de profesionales de enfermería veteranos de once Unidades de enfermería de hospitales españoles y se relacionaron con las respuestas de sus compañeros, recientemente incorporados a los mismos grupos de trabajo.

En primer lugar, se esperaba que la percepción de las dimensiones de la cultura organizacional de las unidades operativas fuese semejante entre los participantes novatos y sus compañeros veteranos, habida cuenta que los procesos de socialización profesional y organizacional están justamente orientados a incrementar el ajuste de los novatos. En este sentido se han verificado los hallazgos de estudios precedentes (Thomas y Anderson, 1999, 2005) según los cuales la discrepancia entre las percepciones se reduce con el tiempo de trabajo en común. Además, en este caso se ha verificado que tales diferencias son más frecuentes y extendidas en aquellos grupos con bajo nivel de acuerdo intragrupo, es decir con cultura débil. Este resultado parece coherente, ya que si las prácticas de socialización o de trabajo no favorecen el desarrollo de un nivel de consenso suficiente sobre la existencia o no de ciertas características organizacionales, tampoco es esperable que exista semejanza en las percepciones entre los diversos subgrupos (novatos vs. veteranos) dentro de cada Unidad de enfermería.

En segundo lugar, en el presente estudio se esperaban diferencias significativas entre los grupos con cultura fuerte y los grupos con cultura débil en las actitudes y comportamientos de los participantes novatos, en concreto en la intención de permanencia-por una parte- y en las OCB- por la otra. En este caso, aunque hay pocos estudios que hayan analizado específicamente el acuerdo cultural como predictor, hemos confirmado los hallazgos precedentes, en el sentido de que una cultura fuerte y compartida (grupos de cultura fuerte) parece ser un predictor de resultados organizacionales deseables (Aarons y Sawitzky, 2006). 
En tercer lugar, se pretendía mostrar que las dimensiones de la cultura organizacional tenían poder predictivo sobre las actitudes y conductas de los miembros novatos y que dicho poder predictivo variaba en función de que los grupos tuviesen una cultura fuerte o débil. En este último apartado también hemos de decir que se ha cumplido el objetivo, dado que las dimensiones de la cultura son predictores eficaces de los resultados actitudinales y conductuales, siendo este poder predictivo más frecuente para los grupos con cultura fuerte. En cualquier caso, es preciso reconocer que el poder predictivo de la cultura organizacional por sí sola es limitado, a la vista de reducida cantidad de varianza que se explica en ambas regresiones. Es posible que la especificidad de las tareas, que supone una gran diferencia entre Unidades dedicadas a atención de consultas externas o de neonatología, por ejemplo, introduzca una fuente de variabilidad que no se ha controlado en este estudio. Por otra parte, es preciso señalar que la recolección de la información no se produjo de forma completa entre todos los integrantes de las Unidades participantes, sino que el muestreo ha sido incidental. Esto implica una fuente de selectividad desconocida, que podría estar distorsionando los resultados.

Diversos hallazgos previos manifiestan que los nuevos empleados usan diferentes estrategias de adquisición de información según sus necesidades, siendo así que algunas fuentes y recursos aparecen como más importantes para las tareas o el dominio de sus roles y otras es más probable que aporten beneficios en términos de actitudes positivas tales como satisfacción, compromiso o ajuste (Comer, 1991; Ostroff y Kozlowski, 1992). En este sentido, es probable que en aquellos grupos de cultura fuerte, los empleados nuevos tomen como fuentes de información a los veteranos y las percepciones compartidas con éstos sobre las características culturales acaben influyendo en sus propios comportamientos y actitudes hacia la organización. Por otra parte, es posible que los grupos de cultura fuerte muestren situaciones en las que el ajuste entre las necesidades personales y las características de la cultura organizacional sean más adecuados, de tal modo que esta congruencia entre la persona y la organización acabe afectando a la permanencia (Wanous, 1992).

\section{Limitaciones e implicaciones prácticas del estudio}

Una de las principales limitaciones de este trabajo consiste en el carácter autoinformado de los datos. En concreto, se ha usado como una de las variables criterio la intención de permanencia en lugar de la permanencia efectiva en la organización. Si bien es cierto que este indicador se puede ver sometido al sesgo de deseabilidad social, algunos autores han señalado que la intención y la conducta efectiva de permanencia tienen elevadas correlaciones (Motowidlo y Lawton, 1984). Como ya se ha referido en el apartado anterior, el procedimiento de muestreo de conveniencia así como el diseño transversal del estudio y la participación de un número muy dispar de integrantes de algunas unidades con respecto a otras son limitaciones que convendría solventar en futuros estudios. Pese a estas falencias, es necesario reconocer la enorme dificultad de este tipo de investigaciones, ya que las organizaciones no siempre son proclives a implicarse en los estudios empíricos y los empleados perciben con recelo las indagaciones que se realizan en ámbitos tan sensibles como sus relaciones con los compañeros y su empresa.

En cuanto a la aplicación de los resultados para la gestión de los Recursos Humanos en las organizaciones, en especial en las instituciones de tipo hospitalario, los hallazgos permiten hacer recomendaciones en orden a fortalecer la cultura de las Unidades de enfermería como un mecanismo para garantizar la permanencia de los nuevos empleados y su comportamiento extra-rol. No obstante, en este estudio no se pretende afirmar que la cultura organizacional sea como una herramienta en la gestión de los Recursos Humanos, si no se toman en cuenta algunos condicionantes de la situación. Un aspecto relevante a considerar es que los grupos pueden llegar a desarrollar normas contraproducentes, las cuales lleven a que la organización sea vista como injusta o incumplidora de sus promesas. De aquí se desprende que la norma implícita que se puede desarrollar en un grupo podría ser la de trabajar lo menos posible y marcharse cuanto antes $\mathrm{y}$, en este caso, a mayor consenso y cultura más fuerte correspondería menor productividad (van Knippenberg, 2000). Otro aspecto a tener en cuenta si se pretende emplear la cultura organizacional como herramienta en la gestión de los Recursos Humanos es que una situación de 
elevado consenso puede tener directamente consecuencias negativas para la organización, ya que el ambiente dentro del grupo resultaría altamente homogéneo y de elevada conformidad con las normas grupales, resultando que la disposición al cambio y a la innovación se anulen, y esto no puede ser un objetivo a largo plazo para ninguna organización actual.

En resumen, los resultados que se plantean aquí arrojan algo de luz sobre la influencia de los factores grupales y organizacionales que afectan a las actitudes y al desempeño de los profesionales de enfermería en las Unidades hospitalarias.

\section{Referencias}

Aarons, G. A. y Sawitzky, A. C. (2006). Organizational culture and climate and mental health provider attitudes toward evidence-based practice. Psychological Services, 3(1), 61-72. doi: http://dx.doi.org/10.1037/1541-1559.3.1.61

Alarcon, G., Lyons, J. B. y Tartaglia, F. (2010). Understanding predictors of engagement within the military. Military Psychology, 22(3), 301-310. doi: http://dx.doi.org/10.1080/08995605.2010.492695

Bauer, T. N. y Erdogan, B. (2011). Organizational socialization: The effective onboarding of new employees. En S. Zedeck y S. Zedeck (Eds.), APA handbook of industrial and organizational psychology, Vol 3: Maintaining, expanding, and contracting the organization (pp. 51-64). Washington, DC: American Psychological Association.

Bauer, T. N. y Erdogan, B. (2014). Delineating and reviewing the role of newcomer capital in organizational socialization. Annual Review of Organizational Psychology and Organizational Behavior, 1(1), 439-457. doi: http://dx.doi.org/10.1146/annurev-orgpsych-031413091251

Bauer, T. N., Bodner, T., Erdogan, B., Truxillo, D. M. y Tucker, J. S. (2007). Newcomer adjustment during organizational socialization: A meta-analytic review of antecedents, outcomes, and methods. Journal of Applied Psychology, 92(3), 707-721. doi:http://dx.doi.org/10.1037/0021-9010.92.3.707

Bauer, T. N, Morrison, E. W. y Callister, R. R. (1998). Organizational socialization: A review and directions for future research. Research in Personnel and Human Resource Management, 16, 149-214.

Birgit, E., Gunnevi, S. y Ann, Ö. (2013). Work experiences among nurses and physicians in the beginning of their professional careers-analyses using the effort-reward imbalance model. Scandinavian Journal of Caring Sciences, 27(1), 36-43. 
Chan, D. (1998). Functional relations among constructs in the same content domain at different levels of analysis: a typology of composition models. Journal of Applied Psychology, 83, 234-246. doi: http://dx.doi.org/10.1037/0021-9010.83.2.234

Chatman, J. A., Caldwell, D. F., O'Reilly, C. A. y Doerr, B. (2014). Parsing organizational culture: How the norm for adaptability influences the relationship between culture consensus and financial performance in high-technology firms. Journal of Organizational Behavior, 35(6), 785-808. doi: http://dx.doi.org/10.1002/job.1928

Comer, D. R. (1991). Organizational newcomers' acquisition of information from peers. Management Communication Quarterly, 5, 64- 89.

Cooke, R. A. y Szumal, J. L. (2000). Using the Organizational Culture Inventory to understand the operating cultures of organizations. En N. M. Ashkanasy, C. P. M. Wilderom y M. F. Peterson (Eds.), Handbook of organizational culture and climate (pp. 147-162). Thousand Oaks, CA: Sage.

Cooke, R. F. y Rousseau, D. M. (1988). Behavioral norms and expectations: A quantitative approach to the assessment of organizational culture. Group $y$ Organization Studies, 13(3), 245-273.

Cooper-Hakim, A. y Viswesvaran, C. (2005). The Construct of Work Commitment: Testing an Integrative Framework. Psychological Bulletin, 131(2), 241-259.

Dávila, M. y Finkelstein, M. A. (2010). Predicting organizational citizenship behavior from the functional analysis and role identity perspectives: Further evidence in Spanish employees. The Spanish Journal of Psychology, 13(1), 277-283.

Glisson, C. y Hemmelgam, A. (1998). The effects of organizational climate and interorganizational coordination on the quality and outcomes of children's service systems. Child Abuse and Neglect, 22, 401-421.
Glisson, C. y James, L. R. (2002). The cross-level effects of culture and climate in human service teams. Journal of Organizational Behavior, 23, 767-794.

Hemmelgarn, A. L., Glisson, C. y Dukes, D. (2001). Emergency room culture and the emotional support component of family-centered care. Children's Health Care, 30, 93-110.

Hosking, D. M. y Morley, I. E. (1991). A social Psychology of Organising People, Processes and Contexts. Londres, UK: Prentice Hall.

Kaissi, A., Kralewski, J., Curoe, A., Dowd, B. y Silversmith, J. (2004). How does the culture of medical group practices influence the types of programs used to assure quality of care? Health Care Management Review, 29(2), 129-138.

Klein, K. J., Conn, A. B., Smith, D. B. y Sorra, J. S. (2001). Is everyone in agreement? An exploration of within - group agreement in employee perceptions of the work environment. Journal of Applied Psychology, 86, 3-16.

Langkamer, K. L. y Ervin, K. S. (2008). Psychological climate, organizational commitment and morale: Implications for Army captains' career intent. Military Psychology, 20(4), 219-236.

Lee, K. y Allen, N. J. (2002). Organizational citizenship behavior and workplace deviance: the role of affect and cognitions. Journal of Applied Psychology, 87(1), 131-140.

Lindell, M. K. (2001). Assessing and Testing Interrater Agreement on a single Target using Multi-Item rating scales. Applied Psychological Measurement, 25(1), 89-99.

Louis, M. R. (1980). Surprise and sense making: what newcomers experience in entering unfamiliar organizational settings. Administrative Science Quarterly, 25(2), 226-251. 
Lyons, J. B., Alarcon, G.: M., Nelson, A. D. y Trataglia, F. (2009, febrero). Employee retention: A Business Case for Engagement. Trabajo presentado al 7th Biennial DEOMI Equal Opportunity, Diversity, and Culture Research Symposium. Florida.

Motowidlo, S. J. y Lawton, G. W. (1984). Affective and cognitive factors in soldier's reenlistment decisions. Journal of Applied Psychology, 69, 157-166.

O'Reilly, C. y Chatman, J (1986) Organizational commitment and psychological attachment: the effects of compliance, identification and internalization on prosocial behavior. Journal of Applied Psychology, 71(3), 492-499.

O'Reilly, C. A., Caldwell, D. F., Chatman, J. A. y Doerr, B. (2014). The Promise and Problems of Organizational Culture CEO Personality, Culture, and Firm Performance. Group \& Organization Management, 39(6), 595-625.

Oliver, L. W., Harman, J., Hoover, E., Hayes, S. M. y Pandhi, N. (1999). A quantitative integration of the military cohesion literature. Military Psychology, 11, 57-83.

Ostroff, Ch. y Kozlowski, S. (1992). Organizational Socialization as a Learning Process: The Role of Information Acquisition. Personnel Psychology, 45, 849-874.

Schein, E. H. (1991). What is culture? En P. J. Frost, L. F. Moore, M. R. Louis, C. C. Lundberg, y J. Martin (Eds.), Reframing organizational culture (pp. 243253). Thousand Oaks, CA: Sage.

Sheridan, J. E. (1992). Organizational culture and employee retention. Academy of Management Journal, 35, 1036-1056.

Thomas, H. D. y Anderson, N. (1998). Changes in newcomers' psychological contracts during organizational socialization: A study of recruits entering the British army. Journal of Organizational Behavior, 19, 745-767.
Thomas, H. D. y Anderson, N. (2005). Organizational socialization: A field study into socialization success and rate. International Journal of Selection and Assessment, 13, 116-128.

Tzeng, H. M., Ketefian, S. y Redman, R. W. (2002). Relationship of nurses' assessment of organizational culture, job satisfaction, and patient satisfaction with nursing care. International Journal of Nursing Studies, 39(1), 79-84.

Van Knippenberg, D. (2000). Work Motivation and Performance: A Social Identity Perspective. Applied Psychology: An International Review, 49(3), 357-371.

Wang, M. O., Zhan, Y., McCune, E. y Truxillo, D. (2011). Understanding Newcomers' adaptability and Work-Related Outcomes: Testing the Mediating Roles of perceived P-E Fit Variables. Personnel Psychology, 64(1), 163-189.

Wanous, J. P. (1992). Organizational entry: Recruitment, Selection, Orientation and Socialization Newcomers. MA.: Addison-Wesley.

Wei, Y. S., Samiee, S. y Lee, R. P. (2014). The influence of organic organizational cultures, market responsiveness, and product strategy on firm performance in an emerging market. Journal of the Academy of Marketing Science, 42(1), 49-70.

Weiss, D. J., Dawis, R. V., England, G. W. y Lofquist, L. H. (1967). Manual for the. Minnesota Satisfaction Questionnaire. illinnesota studies in vocational rehabilitation, No. XXII. Minneapolis: Industrial Relations Center, University of Minnesota.

Wick, E. C., Galante, D. J., Hobson, D. B., Benson, A. R., Lee, K. K., Berenholtz, S. M.,... Wu, C. L. (2015). Organizational Culture Changes Result in Improvement in Patient-Centered Outcomes: Implementation of an Integrated Recovery Pathway for Surgical Patients. Journal of the American College of Surgeons, 221(3), 669-677. 


\section{Apéndice: cultura de los grupos sanitarios}

Basado en Culture of Medical Group Practices (Kaissi et al., 2004)

Todas las preguntas se introducen con el enunciado: "En nuestra Unidad de enfermería:". La escala de respuesta oscila entre 0 (Nada característica) y 4 (Muy característica). Las puntuaciones medias de cada dimensión se calculan para las respuestas de cada participante y luego se agregan en el plano grupal, en función del cumplimiento de los índices de acuerdo.

\section{Cohesión}

a. Hay unas prácticas fáciles de identificar a las que todos tratamos de ajustarnos.

b. Hay un acuerdo general sobre los métodos de tratamiento de los pacientes.

c. Hay un acuerdo amplio y extenso acerca de la mayoría de las cuestiones éticas o morales.

d. Hay un rápido cambio en las prácticas clínicas entre nuestros profesionales cuando las investigaciones indican que eso puede mejorar la calidad.

e. Hay un rápido cambio en las prácticas clínicas entre nuestros profesionales cuando las investigaciones indican que eso puede reducir los costes.

\section{Colegialidad}

a. Hay una gran cantidad de consultas informales entre los profesionales.

b. Hay una gran cantidad de información clínica compartida entre los profesionales.

c. Hay una estrecha relación de camaradería entre los profesionales.

d. Hay un fuerte sentido de pertenencia al grupo.

e. Hay un fuerte sentido de responsabilidad para ayudar a uno de nuestros profesionales si tiene problemas personales.

f. Hay una comunicación abierta y afable entre los profesionales de enfermería y los médicos.

\section{Autonomía}

a. Hay un énfasis en la individualidad de cada profesional, que tiene derecho a ejercer su profesión de acuerdo con su propio estilo.

b. Hay un sentimiento de que cada profesional es autónomo pero que ejerce su práctica en la misma organización.

c. Hay un alto grado de tolerancia a las prácticas individuales de cada profesional para tratar a los pacientes. 